\title{
Exploring the Influence of Simulated Road Environments on Cyclist Behavior
}

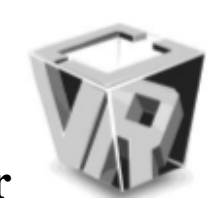

\author{
Jing Xu ${ }^{1}$, Yingzi Lin* ${ }^{1}$, David Schmidt ${ }^{1}$ \\ ${ }^{1}$ Intelligent Human Machine Systems Lab, Department of Mechanical and Industrial Engineering, College of Engineering, \\ Northeastern University, Boston, MA 02115, USA
}

Abstract - An increasing number of people are realizing the advantages of bicycling, which has caused bicyclist safety concerns and awareness to rise accordingly. This study aims to investigate the capability of combining Virtual Reality technology and bicycle simulation for bicyclist behavior studies. An immersive interactive bicycle simulation was developed to explore how subject performance is influenced by virtual road environments through a well-controlled experiment with Oculus Rift headset. 30 people from 18-25 years old were chosen to be subjects, as they are in the highest injury rate percentile. Results showed that the existence of bike lanes influences cyclist reactions, causing earlier and more braking to occur. Road hazard simulation and "Distance to Brake to Stop" measurement can provide useful insight into individual cyclist reactions to different types of road hazards. This study has provided evidence that given the nature of cycling on roads, virtual reality technology can serve as both a safe and effective method to conduct more in-depth behavior studies.

Index Terms - bicycle simulation; oculus rift; user performance; hazards reaction; bicyclist safety.

\section{INTRODUCTION}

Cities in the United States have been experiencing a rapid increase in bicycle ridership over the past decade. This increase correlates to a rise in cyclist accidents (Sherony and Zhang 2015). As cyclists as vulnerable road users are still less discussed than others in research, the necessity to address concerns and awareness regarding bicyclist safety needs to rise accordingly. Existing studies that focus on cyclists as road users do so by identifying behavioral differences, and the individual and environmental factors that cause them, e.g. gender, experiences, bicycle facilities, and road hazards, etc. Literature review has found that the majority of research methods used in bicycle safety were based on public records (Cai et al. 2016; Pulugurtha and Thakur 2015), field / field video observation (Wolfe et al. 2016; $\mathrm{Xu}$ et al. 2016; Kay et al. 2014; Khan and Raksuntorn 2001; Wheeler, Conrad, and Figliozzi 2010), GPS data (ElGeneidy, Krizek, and Iacono 2007; Chen and Shen 2016; de Waard, Edlinger, and Brookhuis 2011; Ducheyne et al. 2014), case studies/interviews/questionnaires (Beck et al.

\footnotetext{
${ }^{*}$ E-mail: yi.linenortheastern.edu
}

2016; Schepers and den Brinker 2011; Colwell and Culverwell 2002), as well as new automated cyclist counting technologies for on-road testing (Proulx, Schneider, and Miranda-Moreno 2016; Kocamaz, Gong, and Pires 2016; Belgiovane and Chen 2016). Due to the variety of study methods and small data samples, however, some disagreements exist within the reviewed literature on cyclist safety and behavior studies (DOT 2015). For example, some studies included in this review found that separated bike lanes exhibit a reduction in crashes, or no crash incidence increase, when compared with roads without bicycle infrastructure. Others found that the implementation of separated bike lanes increases the total number of crashes, but provide a lack of traffic volume data. Meanwhile, because of the methods used, the behavioral differences identified in overall choices made by the cyclist population are at a macroscopic level. Other collection methods may be needed to identify underlying reasons and individual features for such differences. There are studies started to address cyclist safety research by equipping cyclists with tracking facilities for in-field bicyclist data (Schleinitz et al. 2016; Vansteenkiste et al. 2014a; Vansteenkiste 2015). However, subject ethical and pragmatic concerns still limit research capable of providing real-time measurements of human performance to study cyclist behavior. Therefore, there is a need for novel methods and technology that allows for accurate, real-time data collection in realistic scenarios while guaranteeing user safety.

Virtual Reality (VR) technology is now commonly used in many domains for its ability to give users a realistic experience and expose their natural behavior through interactive, immersive environments (Lin 2017; Cai, Lin, and Cheng 2010; $\mathrm{Xu}$ and Lin 2014). This makes VR an ideal medium to control different situations for cyclists and thus accurately provide a means for behavior comparison. Though it has been widely used in driver behavior studies in the past decades (Lin 2010; Cai and Lin 2012; 2011), to date, similarly advanced simulation technology has barely been developed for bicycling, and few studies have explored VR as an advanced way to understand cyclist behavior. In line with recent attempts to combine VR technology and bicycling, the majority of studies have explored its use in the fields of training, rehabilitation, or a combination of exercise and entertainment. For example, a Bostonbased company, VirZoom (VirZoom 2015), powered users 


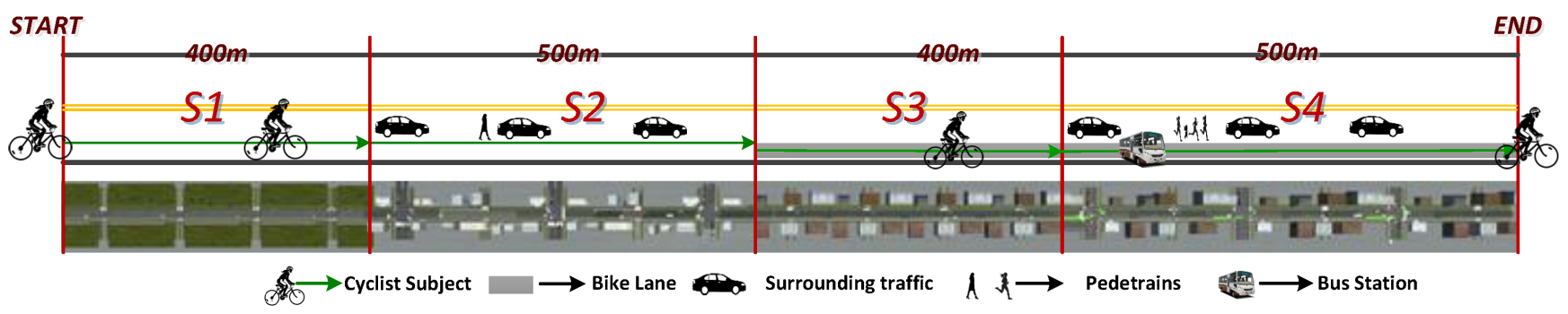

Figure 1: The layout of the virtual environment

exercise with video games using a stationary bike and VR headset. Legrand et al. (Legrand et al. 2011) applied a stationary bike to study the capability of VR to enhance exercise performance, enjoyment, and dissociations. Morel, M.s team (Morel et al. 2015) let patients ride a bicycle to follow a central line on a virtual road while keeping their centre of pressure stable. In these studies, the bike is used as an essential tool in VR for balance assessment or rehabilitation, but can be replaced by other forms of moderate-to-intense physical activity (e.g. standing, walking).

VR technology has been used extensively for motor vehicle behavior or driver behavior analysis for decades, but is currently an underutilized tool for cyclist behavior. Regarding current VR applications in cyclist behavior studies, Kosaka, H.s team (Kosaka and Noda 2015) explored the potential of virtual environments (VE) as an educational method for safe bicycle riding at intersections to evaluate actual cycling behaviors. A team from Tokyo Institute of Technology proposed the study of bicycle collision analysis by using a vehicle-driving simulator and a developed bike simulator to examine various road designs and traffic situations to study bicycle facility design (Suzuki et al. 2011; SUZUKI, MIYANOUE, and Student 2013). Yang and Wu (Yang and Wu 2017) recently applied a lab-based bike simulation to provide authentic riding conditions for investigating hazard perception performance. In Europe, a recent study from Monash University used existing cyclist crash data along with unique cyclist exposure data to develop road infrastructure prototypes; a cycling simulator was then used to evaluate the effectiveness of these prototypes (Stevenson et al. 2014). In the US, the Hank Virtual Environments Lab in the University of Iowa houses a bicycle simulator in a virtual environment that focuses on the decision-making process of children when crossing roads, as well as how they cross traffic-filled roads (Plumert, Kearney, and Cremer 2004; Stevens et al. 2012; Grechkin et al. 2013). Their research revealed key differences in children and adults crossing trafficfilled roads (Plumert, Kearney, and Cremer 2004). One interesting experiment used a programmatically controlled peer in VE to ride along a young cyclist to study how social interaction with a peer influences childrens riding behavior (Babu et al. 2011). Multiple screens were used in these simulations to achieve VR immersion for test subjects. Since 2014, the worlds' technology giants have made significant moves towards VR technology, especially VR Headmounted display (HMD) devices. The "Oculus Rift" has gained great popularity as a first consumer version low-cost VR platform, which has made great improvements compared to previous HMDs (Oculus 2016). The advantage of a high-fidelity 360-degree field of regard in a Virtual Environment provides full visual immersion and presence to users, which has implications for vehicle simulation research (Alshaer, Regenbrecht, and OHare 2017). To the best of our knowledge, we are not aware of any studies regarding bicycle simulation being viewed with HMD. Therefore, we sought to explore use of the new HMD generation, in this case, the Oculus Rift DK2, for examining cyclist behavior in VR simulation. The objective of this research is to explore the potential of combining advanced VR technology and cyclist simulation for the purpose of studying how road environmental factors influence cyclist behavior, and how cyclists react to hazard events in VR set-ups.

\section{BiKe Simulation DeSign II.I. VIRTUAL ENVIRONMENT DESIGN}

The bike simulator development provides a combination of bicycle physics, controlled virtual environment, and a VR Head Mounted Display- Oculus Rift DK2. This study built up bicycle physics with $\mathrm{C \#}$ in Unity for cycling simulation. The bike physics model was simplified from Meijaard and Papadopoulos (Meijaard et al. 2007)s bike dynamics model; relevant parameters mainly follow AASHTO guidelines (NHTSA 2010) and Unity Wheel Collider (Unity 2016) Version 5.3. The virtual environment is a 1900 meter (1.1 miles) straight path with traffic lights, signs and traffic. The straight path is divided into four sections, as seen in Figure 1. Cyclists start with no bike lane and very limited traffic in the first $400 \mathrm{~m}(\mathrm{~S} 1)$. The following $500 \mathrm{~m}$ (S2) is a shared road with three intersections and controlled traffic. The next $400 \mathrm{~m}$ (S3) introduces a bike lane with no traffic to encounter. Over the last $500 \mathrm{~m}$ (S4), cyclists will again encounter three intersections with surrounding traffic with bike lane facilities. The surrounding vehicles in all sections consisted of a series of cars traveling in vehicle lanes at controlled speeds and routes.

The course consists of a $9.6 \mathrm{~m}$ wide two-way road at a level grade. This follows the recent version of 'AASHTO (NHTSA 2010) Guide for the Development of Bicycle Facilities' guidelines. Figure 2 shows the road configurations presented in the simulated virtual city. Figure 2a (S3\&S4) shows a route with a standard bicycle lane (an exclusive lane for cyclists) on both sides. Figure $2 \mathrm{~b}$ (section 


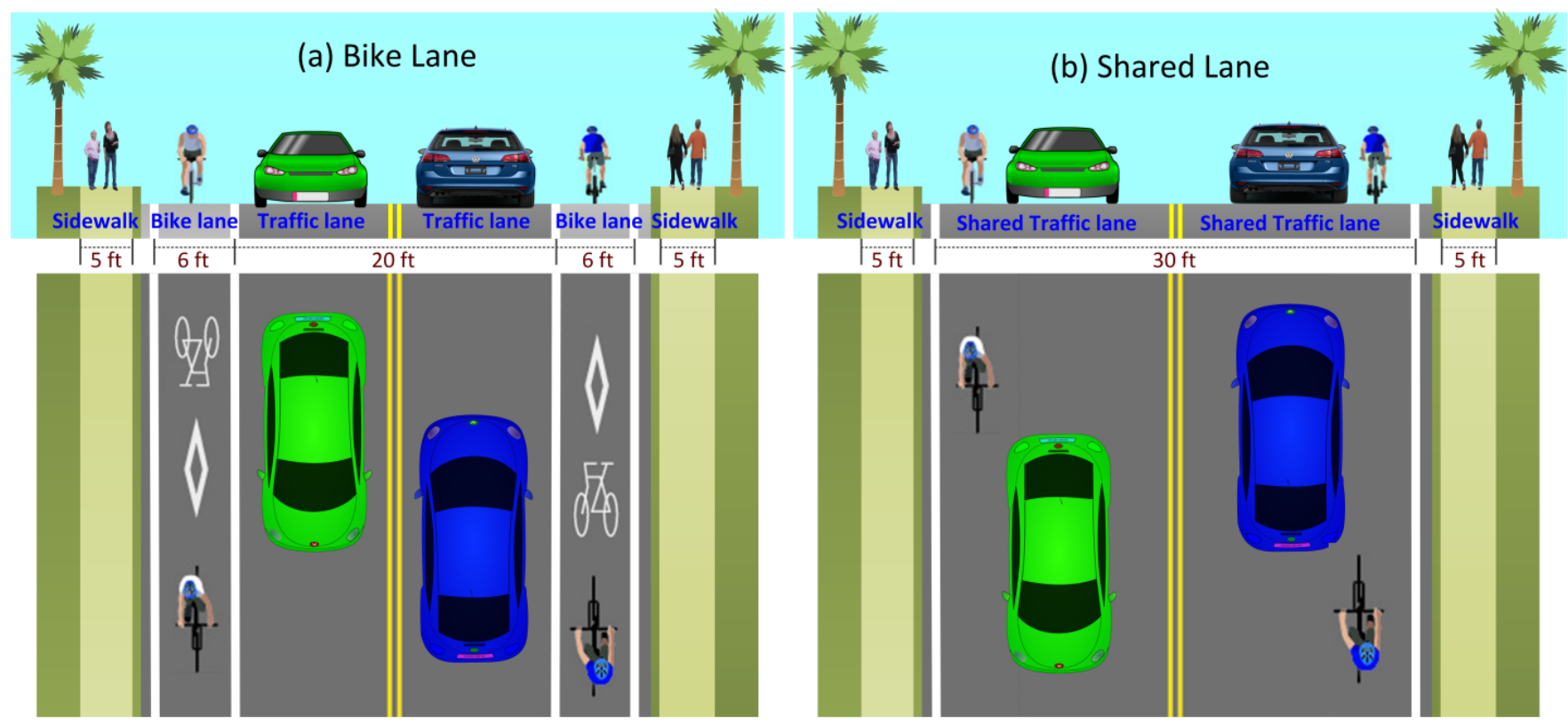

Figure 2: Road configuration and dimensions in simulated city

1\&2) refers another typical type of bike lane a shared lane that cyclists and cars both have the same rights to. Car drivers are supposed to share these lanes carefully with cyclists, give cyclist at least 3 feet $(0.91 \mathrm{~m})$ when passing, and are not supposed follow too closely (NHTSA 2010). In configurations both with and without bike lanes, paved sidewalks run along both sides of the road. The overhead view of the intersection shown in Figure $3 \mathrm{c}$ represents a new type of lane - a bicycle box. A marked green box represents space for bicyclists to wait at red lights. Cyclists queue up in the green space, while drivers are required to yield to cyclists, waiting behind the box while stopped. This allows cyclists to get an important head-start on traffic, especially when a cyclist lane change is upcoming (Plumert et al. 2011). The standard traffic light is incorporated with a fourth bike light that will turn green when cyclists can cross the intersection directly.

The following factors from a recent cyclist safety report were considered for virtual environment design (Sherony and Zhang 2015): (1) most of the bicyclist fatal crashes (71\%) happen on urban roads; (2) the highest crash percentages occur during daylight conditions, which includes $78 \%$ of injury crashes and 52\% of fatal crashes; (3) the majority of crashes each day occur during afternoon rush hour, while the majority each year occur in the summer, especially in the colder states. Accordingly, our simulated environment was designed as a coastal city landscape on a clear sunny day. Figure 3 shows some scenarios seen by test subjects during the experiment.

\section{II.II. ROAD HAZARDS DESIGN}

Regarding road hazard design, we found that motor vehicles are involved in approximately one-third of all bicyclerelated brain injuries and $90 \%$ of all fatalities resulting from bicycle crashes. $75.4 \%$ of injury crashes and $76.6 \%$ of fatal crashes happen after vehicles met bicyclist on the road-

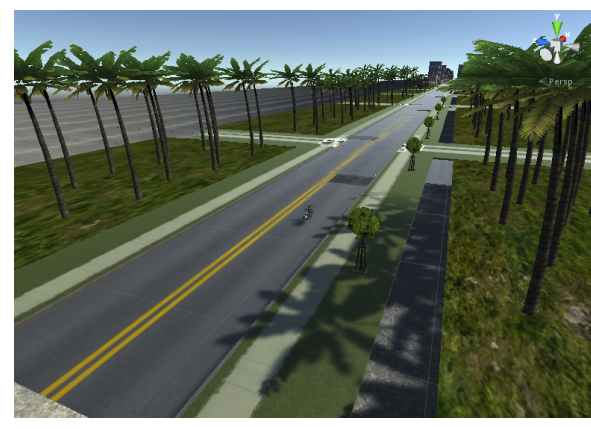

(a) low traffic, shared road

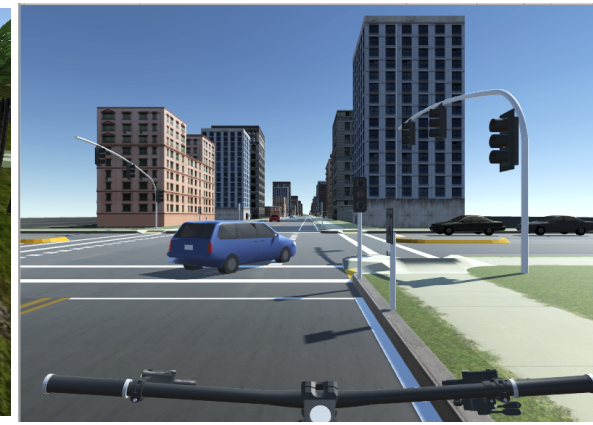

(b) high traffic, shared road with traffic

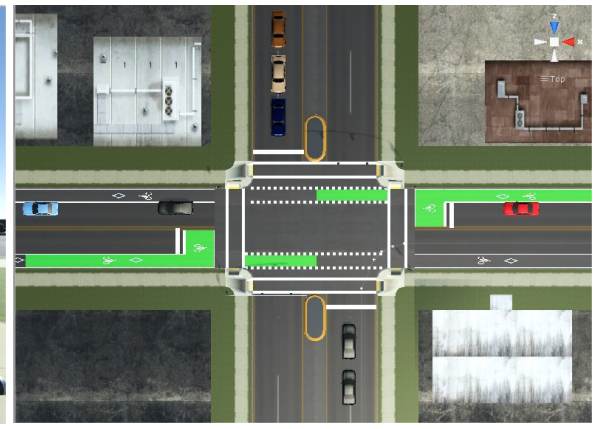

(c) high traffic, intersection with bike box

Figure 3: Screenshot of virtual scenarios in simulated city 
Table 1: Classification and short description of the included road hazards

\begin{tabular}{|c|c|c|c|c|c|c|c|}
\hline No. & Name & Scenario description & Hazard location $^{\text {a }}$ & Hazard description & \multicolumn{2}{|c|}{ Hazard type } & Event location $^{b}$ \\
\hline H1 & $\begin{array}{l}\text { Pullout vehicle from } \\
\text { the same side }\end{array}$ & $\begin{array}{l}\text { Intersection; low traffic; } \\
\text { shared road; }\end{array}$ & In front & $\begin{array}{l}\text { A car turns right } \\
\text { onto the cyclists road } \\
\text { from a 4-way intersection }\end{array}$ & Single & Potential & 457.0 \\
\hline $\mathbf{H 2}$ & Pedestrian crossing & $\begin{array}{l}\text { Straight road; low traffic; } \\
\text { shared road; } \\
\text { crowded commercial area }\end{array}$ & $\begin{array}{l}\text { In front, } \\
\text { from the right }\end{array}$ & $\begin{array}{l}\text { A pedestrian suddenly } \\
\text { steps into road }\end{array}$ & Single & Materialized & 550.7 \\
\hline H3 & $\begin{array}{l}\text { Left cross } \\
\text { vehicle }\end{array}$ & $\begin{array}{l}\text { Intersection; low traffic; } \\
\text { shared road; }\end{array}$ & $\begin{array}{l}\text { In front, } \\
\text { from the left }\end{array}$ & $\begin{array}{l}\text { A car turns left onto } \\
\text { the cyclists road from } \\
\text { a 4-way intersection. }\end{array}$ & Single & Materialized & 648.0 \\
\hline H4 & $\begin{array}{l}\text { Right hook } \\
\text { vehicle with } \\
\text { blocked view }\end{array}$ & $\begin{array}{l}\text { Approaching intersection; } \\
\text { low traffic; } \\
\text { shared road }\end{array}$ & $\begin{array}{l}\text { In front, } \\
\text { from the right }\end{array}$ & $\begin{array}{l}\text { A bus blocks the cyclists view } \\
\text { of a car turning right off of the same } \\
\text { road without stopping or yielding. }\end{array}$ & Dual & Materialized & 848.5 \\
\hline H5 & $\begin{array}{l}\text { Left cross } \\
\text { vehicle }\end{array}$ & $\begin{array}{l}\text { Intersection; high traffic; } \\
\text { bike lane; }\end{array}$ & $\begin{array}{l}\text { In front, } \\
\text { from the left }\end{array}$ & $\begin{array}{l}\text { A car turns left onto } \\
\text { the cyclists road from } \\
\text { a 4-way intersection. }\end{array}$ & Single & Potential & 1357.5 \\
\hline H6 & $\begin{array}{l}\text { Bus block bike } \\
\text { lane with hidden } \\
\text { pedestrian }\end{array}$ & $\begin{array}{l}\text { Straight road; high } \\
\text { traffic; bike lane } \\
\text { shared road }\end{array}$ & In front & $\begin{array}{l}\text { A bus occupies the bike lane so that } \\
\text { cyclist has to change lane to pass the } \\
\text { bus, followed by a group pedestrians } \\
\text { from the curb running across the road. }\end{array}$ & Dual & Materialized & 1471.0 \\
\hline H7 & $\begin{array}{l}\text { Pullout vehicle } \\
\text { from the same side }\end{array}$ & $\begin{array}{l}\text { Crossing intersection; } \\
\text { high traffic; bike lane }\end{array}$ & In front & $\begin{array}{l}\text { A car turns right onto } \\
\text { the cyclists road from } \\
\text { a 4-way intersection. }\end{array}$ & Single & Potential & 1572.7 \\
\hline H8 & $\begin{array}{l}\text { Right hook vehicle } \\
\text { with blocked view }\end{array}$ & $\begin{array}{l}\text { Straight road; } \\
\text { high traffic; bike lane }\end{array}$ & $\begin{array}{l}\text { In front, } \\
\text { from the right }\end{array}$ & $\begin{array}{l}\text { A bus blocks the cyclists view of } \\
\text { a car turning right off of the same road } \\
\text { without stopping or yielding. }\end{array}$ & Dual & Materialized & 1759.8 \\
\hline
\end{tabular}

Referred to the cyclist perspective.

b The collision/potential collision point.

way. Many of these collisions between bicycles and motor vehicles occur at intersections (Sherony and Zhang 2015). From investigating the Pre-Event vehicle movement from vehicle-bike accidents, we found that for crashes resulting in injury, most vehicles were going straight and many were turning right; while for fatal crashes, most vehicles were going straight. With respect to Pre-Crash Action scenarios for bicyclist related accidents, the American Bicycling Education Association defines three types of accidents that most commonly happen involving bicyclists and motorists (Dan 2012). The first one is Pullout Risk vs. Positioning. This accident usually happens when the cyclist goes through an intersection at the same time a car pulls out from a side street, driveway, or parking lot, to the right of the cyclist. The driver simply does not look closely and pulls out. The second type of accident is a Left Cross. The motorist and bicyclist approach the intersection from opposite directions, and as they enter the intersection, the vehicle turns left, colliding with the cyclist (Dan 2012). The third one, which is the most common and dangerous, is the Right Hook. A classic right hook crash is when a bicyclist riding near the road edge attempts to pass straight through an intersection, while a vehicle traveling in the same direction proceeds to turn right, cutting off the cyclist and causing a crash.

With thought towards these behaviors and types of accidents, the simulation will examine common scenarios and observe cyclist responses to prevent further accidents involving cyclists. Therefore, the planned road events in this study include pedestrian crossing; vehicles occupied the bike lane, right hook, left cross, and pullout cars. Eight hazardous scenarios were randomly spread out in section 2 and 4, and the classification, as well as short description of each scenario, are shown in Table 1 . The potential hazard means a situation that may turn into an actual hazard. It will not cause any crash as different pre-designed travel speed for both vehicle and bicycle, but the cyclist will see it. The materialized hazard will cause a crash, which requires cyclist slowdown or immediate evasive action to avoid the accident. The dual hazard means more than one event happens at the same time or consequently, which requires multiple cyclist reactions.

\section{II.III. APPARATUS}

This virtual bicycle simulation utilized apparatus in the Northeastern University Intelligent Human-Machine System (IHMS) Laboratory. A head-mounted display (Oculus Rift DK2) device was used to display the virtual environment. The viewpoint of the virtual environment was adjusted for each participants height, eye to neck distance (vertical and horizontal), IPD, and eye relief. The Oculus Rift contained two small LCOS displays, each with a resolution of $1280 \times 1024$. An Intersense Vistracker IS-1200 was fitted to measure orientation and position (Oculus 2016). Participants translated through the virtual environment via a keyboard that used arrow keys to control the speed of forward motion directly, and the space key as a handbrake. The Oculus Rift is connected to a DELL Minitower 4500 with an NVidia GTX 970 graphics card.

\section{METHOD}

\section{III.I. Participants}

Participants recruited for this study included 30 volunteers (15 female, 15 male) with the only criteria being that subject age falls between 18-25 years (Mean $=21.57$; $\mathrm{SD}=1.30$ ). Recent Reports show that the most common age to be involved in a cycling accident requiring Emergency Medical Services (EMS) is around 23 years old, the highest bicycle accident injury rate occurred in the 20 -to- 24 age group in 
2014 (NHTSA 2016). All participants were required to be in good health and fully comfortable with English, and have normal or corrected-to-normal vision. All subjects have at least four years living experience in Boston. Regarding how often subjects ride a bicycle, $16.67 \%$ responded 'regularly' (3-5 times/week), and $63.33 \%$ reported 'occasionally.' As for the environment they commonly ride in, $50 \%$ reported 'urban roads', $10 \%$ 'rural', and $23.33 \%$ 'both'. When asked whether they noticed the roads along their commute have bike lanes, only $1 / 3$ replied "Yes" and $16.67 \%$ admitted to "I do not know." $96.67 \%$ of participants did not have previous experience with HMD, and none of them had previous bike video game or bicycle simulator experience. The study was approved by the Northeastern University Institutional Review Board (IRB) and all investigators took the NIH human subject protection training and received certification. Signed informed consent was obtained before participation in the study from all participants, and \$10 gift cards were paid as compensation.

\section{III.II. Experimental Procedure}

The experiment consisted of three sessions: preparation, practice, and testing sessions. The whole experiment lasted an average of 30 minutes for each participant. The participant was first given an experiment overview, was asked to read and sign a consent form and completed a background survey. The participant was then asked to wear the Oculus Rift and input his/her sit height and eye span for calibration until they could see the virtual scenario clearly and comfortably. Because of the 360-degree field of regard of the HMD, the participant was asked to turn his/her head in different directions and move their upper body to feel how changes in position affect eye view. This provided the opportunity to realize that they can use the headset to check surrounding traffic and the road environment just as they would in real life. Following the preparation session was a practice session in which the participant saw a test scene, and was instructed to move forward down a straight path by controlling bike speed, while simultaneously receiving optic flow information through Oculus Rift. The practice session provided participants the opportunity to learn how to steer, accelerate/decelerate, brake, and become familiar with the sensitivity of all motions on the keyboard. This session would continue until the participant feels familiar and very comfortable with the controls. During the testing section, the participant rode through the virtual town with cyclist lights at intersections. The participant was instructed to follow traffic rules to complete travel through four Sections, as shown in Figure 1. When approaching the course end, participants will see road barriers and signs stating "Save Data". There was no time limitation for the procedures, and the participant was free to ask to stop at any time. Performance metrics were recorded during the entire course.

\section{III.III. DATA ANALYSIS}

Bicyclist behavior measures were automatically recorded by simulation software developed for the test course, which includes velocity, lateral lane position, steering input, lean angle, handbrake action, etc. Speed performance and bike lane position and are two key metrics for cyclist riding performance evaluation. Speed was used mainly for analyzing road hazard scenarios, which can reflect cyclist responses and reactions. For lane control analysis, measures computed from the simulator data were average Bike Lane Departure (BLD), BLD Variability, and Percentage of Time Out of Lane. Across the entire course and for each section, average BLD was calculated by averaging the differences between the middle-line of the bike lane (measured from environment model) and bicycles Center of Mass position (derived from simulator data output). The bike lane width was $1.5 \mathrm{~m}$ ( 5 feet) from the curb face to the bike lane stripe, the width of bike-rider system is $0.75 \mathrm{~m}$, the designed eye point height is $2.5 \mathrm{~m}$, and cyclists were considered to be out of the lane when the bicycles Center of Mass crossed the bike lane marker, $0.75 \mathrm{~m}$ from center (NHTSA 2010).

Data was analyzed with R-Studio (Version 2.6.5). A Dixon test was used for checking subject outliers. As a result, all 30 test subject data was utilized for all analyses other than the percentage of time out of the lane, which did not consider data from subject 28 . The survey revealed that subject 28 did not have any previous bicycle experience and also did not pay attention to the bike lane while riding in the virtual environment. Statistical significance of differences was calculated using ANOVA. In the analyses, effect sizes are reported as partial eta squared $\left(\eta_{p}^{2}\right)$.

\section{RESULTS}

Cyclist performance was analyzed over the course for 30 subjects. The average total travel time across all subjects is 336.528 seconds [ $\mathrm{SD}=20.682$ ], average cycling speed is $22.684 \mathrm{~km} / \mathrm{h}$ [SD $=5.594]$, and the average bike lane departure is 0.589 meters [SD $=0.603$ ]. The findings from the survey after experiment indicate that $73.3 \%$ of participants felt the "road with bike lane" was their most comfortable cycling environment. Regarding the discomfort level from using the VR headset, $83.3 \%$ of participants report "not at all" or "slightly", and $76.8 \%$ of participants rate above 3 (scale $1-5)$ regarding the realistic feel of simulation.

Environmental Factors Environmental factors (Bike Lane Road vs. Shared Lane Road; Low Traffic vs. High Traffic) were taken as within group variables to see how cyclist performance differed from riding on different road configurations and with different traffic types. A two way ANVOA was carried out for average speed on the effect of Road Type and Traffic Type. The significant main effects of Road Type $\left(F_{(1,116)}=6.168, p=0.014, \eta_{p}^{2}=0.050\right)$ and Traffic Type $\left(F_{(1,116)}=227.684, p<0.001, \eta_{p}^{2}=\right.$ $0.662)$ were tested. There was a significant interaction between the effects of Road Type and traffic type, $F_{(1,116)}=$ $7.342, p=0.008, \eta_{p}^{2}=0.060$. Specifically, regarding both shared lane road and bike lane roads, cyclists on low traffic proved to have significantly higher speed in high traffic areas, $F_{(1,117)}=73.38, p<0.001$, and $F_{(1,117)}=$ $151.70, p<0.001$. Regarding the low traffic area, cyclists on the bike lane road have significantly higher speed than those on the shared road, $F_{(1,117)}=4.59, p=0.034$. 

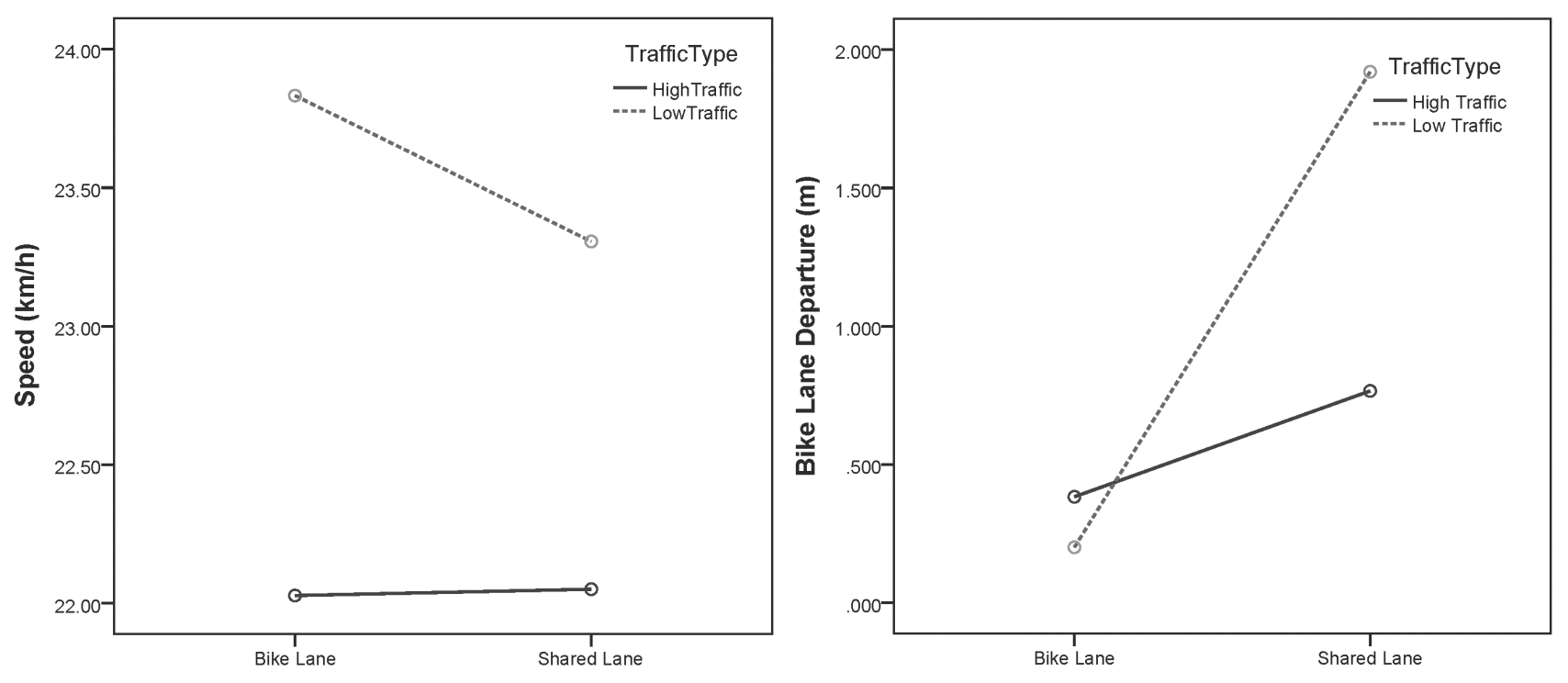

Figure 4: The interaction effect between road type and traffic type. Left: Speed $(\mathrm{km} / \mathrm{h})$; Right Bike Lane Departure $(\mathrm{m})$

The Road Type Traffic Type ANOVA on average lane departure highlighted significant main effects of Road type $\left(F_{(1,108)}=65.925, p<0.001, \eta_{p}^{2}=0.379\right)$ and Traffic Type $\left(F_{(1,108)}=14.078, p<0.001, \eta_{p}^{2}=0.115\right)$. An interaction effect between road type and traffic type, $F_{(1,108)}=26.653, p<0.001, \eta_{p}^{2}=0.198$, was significant. Specifically regarding the shared lane road, cyclists in low traffic areas proved to have significantly higher lane departure than in high traffic areas, $F_{(1,109)}=27.17, p<0.001$. On the low traffic road, bike lane departure is significantly lower while riding on the bike lane than on the shared road, $F_{(1,109)}=85.92, p<0.001$. However, the high traffic area did not show significant differences in bike lane departure whether there was bike lane or not, $F_{(1,109)}=2.27, p=$ 0.135 . Additionally, the indicated BLD variability was also significantly lower on the bike lane road than on the shared lane road, $F_{(1,58)}=8.297, p=0.006, \eta_{p}^{2}=0.125$. The percentage of time out of lane was also compared between S3 and S4, both bike lane roads. It is found that cyclists riding on the low traffic bike lane road show significantly lower times out of lane than on the high traffic bike lane $\operatorname{road}(\mathrm{S} 3: 4.2 \%[\mathrm{SD}=0.158]$ vs. $\mathrm{S} 4: 12.5 \%[\mathrm{SD}=0.109])$, $F_{(1,56)}=5.41, p=0.023, \eta_{p}^{2}=0.088$.

Normality checks and Levene's test were carried out and the assumptions were met. Figure 4 presents the interaction effects.

Road Hazards When analyzing specific events in a driving simulator, it is typical to examine speed-related differences by looking at the sections in a scenario proximal to the beginning of the hazardous event. Using the AASHTO Distance to Brake to Stop Formula (NHTSA 2010) to get the minimum stopping distance for a bicycle travelling at $25 \mathrm{~km} / \mathrm{p} / \mathrm{h}$ on a level road, distances 30 meters before and 20 meters after a road event were defined as the Event Window for calculating Crossing Speed (CT) and Crossing

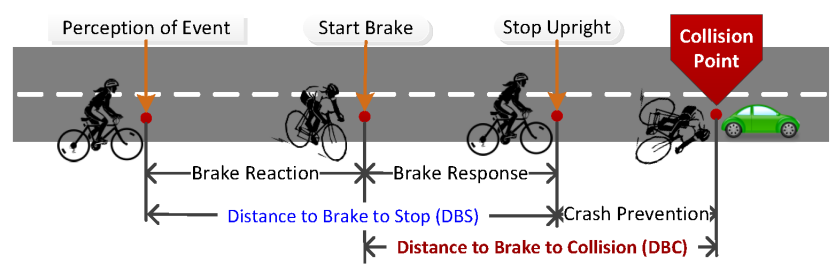

Figure 5: The definition of distance/time to Brake to Collision

Time $(\mathbf{C T})$. The "Distance To Brake To Stop Formula" can calculate the estimated Distance to Brake to Stop (DBS): $D B S=\frac{v^{2}}{254(f \pm G)}+\frac{v}{1.4}$, where: $v=$ Velocity $(\mathrm{km} / \mathrm{h}), f=$ coefficient of friction, $G=$ grade $(\mathrm{m} / \mathrm{m})$. Here we take $G$ as 0 for a ground level road, and $f$ is $25 \%$. This method observes DBS that is a sum of two components; brake reaction distance, and break response distance. This estimation relies on two main assumptions that average brake reaction time is $2.5 \mathrm{~s}$, and that the cyclist will come to a complete stop. In this study, the Distance to Brake to Collision (DBC) and Time to Brake to Collision (TBC) was defined to describe cyclists actual behavioral response to the hazardous event, as shown in Figure 5. The DBC is also a sum of two components: Brake Response Distance and Crash Prevention Distance. Both observations include Break Response Distance, but DBS focuses on the reaction time before this, while DBC focuses on the remaining time after, before a crash would occur. The different focus of DBC provides a different insight, how close to the potential accident the cyclist reaction occurs. DBC and TBC can be calculated precisely from subjects bicycle simulation data. The nondeceleration rate reveals the percentage of subjects who did not brake, but crossed hazards with a maintained speed. Descriptive results for average performance are provided in Table 2 . 
Table 2: Cyclist safety measures for different road hazards

\begin{tabular}{|l|l|l|l|l|l|l|l|}
\hline Hazards Type & Event & $\begin{array}{l}\text { Average } \\
\text { CT }(\mathbf{s})\end{array}$ & $\begin{array}{l}\text { Average CS } \\
\text { MEAN(SD)(km/h) }\end{array}$ & $\begin{array}{l}\text { Estimated } \\
\text { DBS (m) }\end{array}$ & $\begin{array}{l}\text { Average } \\
\text { DBC (m) }\end{array}$ & $\begin{array}{l}\text { Average } \\
\text { TBC (s) }\end{array}$ & $\begin{array}{l}\text { Non-decele } \\
\text { ration rate }\end{array}$ \\
\hline \multirow{3}{*}{ Single/Potential } & H1 & 9.597 & $21.300(3.453)$ & 21.683 & 33.286 & 8.279 & $16.67 \%$ \\
\cline { 2 - 8 } & H5 & 11.69 & $19.129(4.705)$ & 22.977 & 26.827 & 8.379 & $6.67 \%$ \\
\cline { 2 - 8 } & H7 & 10.296 & $20.053(4.566)$ & 21.295 & 23.259 & 6.472 & $10 \%$ \\
\hline \multirow{2}{*}{ Single/Materialized } & H2 & 9.221 & $21.379(3.266)$ & 25.707 & 7.891 & 2.191 & $23.33 \%$ \\
\cline { 2 - 8 } & H3 & 12.353 & $19.533(5.386)$ & 23.265 & 15.365 & 6.468 & $6.67 \%$ \\
\hline \multirow{3}{*}{ Dual/Materialized } & H4 & 10.133 & $19.970(4.045)$ & 22.96 & 27.69 & 6.603 & 0 \\
\cline { 2 - 8 } & H6 & 17.637 & $17.969(5.175)$ & 20.736 & 21.759 & 12.404 & 0 \\
\cline { 2 - 8 } & $\mathrm{H} 8$ & 10.582 & $19.437(3.682)$ & 22.218 & 27.052 & 6.816 & 0 \\
\hline
\end{tabular}

Cyclists responded almost similarly well to the three single potential hazards. DBC was relatively high for all three hazards, showing that most cyclists had no trouble noticing and deciding to react to the hazard. All single potential hazards have very different non-deceleration rates. Nondeceleration rates were low, under $10 \%$ with the exception of $\mathrm{H} 1 . \mathrm{H} 1$ is the only single potential hazard occurring with no bike line present. This increase in non-deceleration may show that some subjects feel more comfortable using lateral movement as a reaction over braking with the absence of a bike lane. Cyclists responded very differently to the single/materialized hazards. Both hazards occurred before the bike lane was introduced, but $\mathrm{H} 2$ still had a higher nondeceleration rate and the lowest DBC. These rates would suggest that more people see a pedestrian crossing as less of a hazard than a turning car when there is no bike lane present, but adding a bike lane changes this. There was a drastic change in behavior to a crossing pedestrian when a bike lane was introduced, with a $0 \%$ non-deceleration rate, as well as a higher DBC. All dual/materialized hazards had a non-deceleration rate of $0 \%$, which shows that every cyclist regarded a right turning car as a hazard, regardless of bike lane. These differences show that cyclist performance has a dependence on the road environment, and type of hazard introduced.

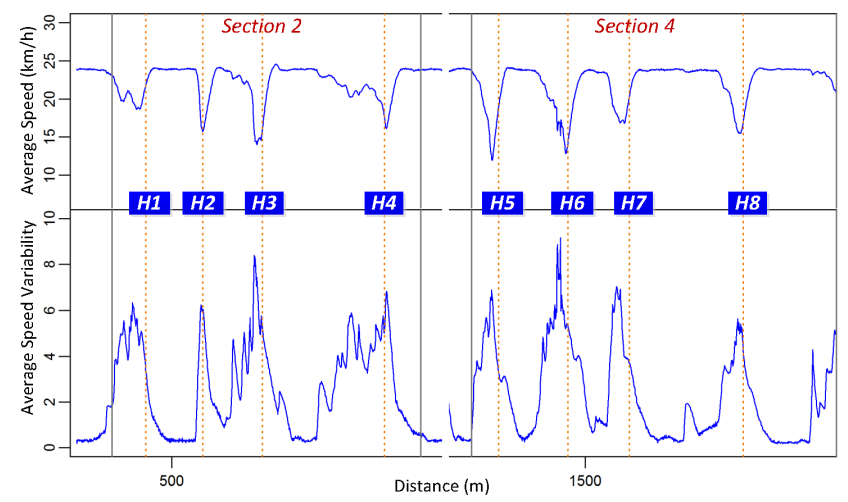

Figure 6: Average speed and variability trajectories at high traffic section with road hazards

To ease consistency and comparability, speed measurement is sampled every 0.5 meters from the recorded data,
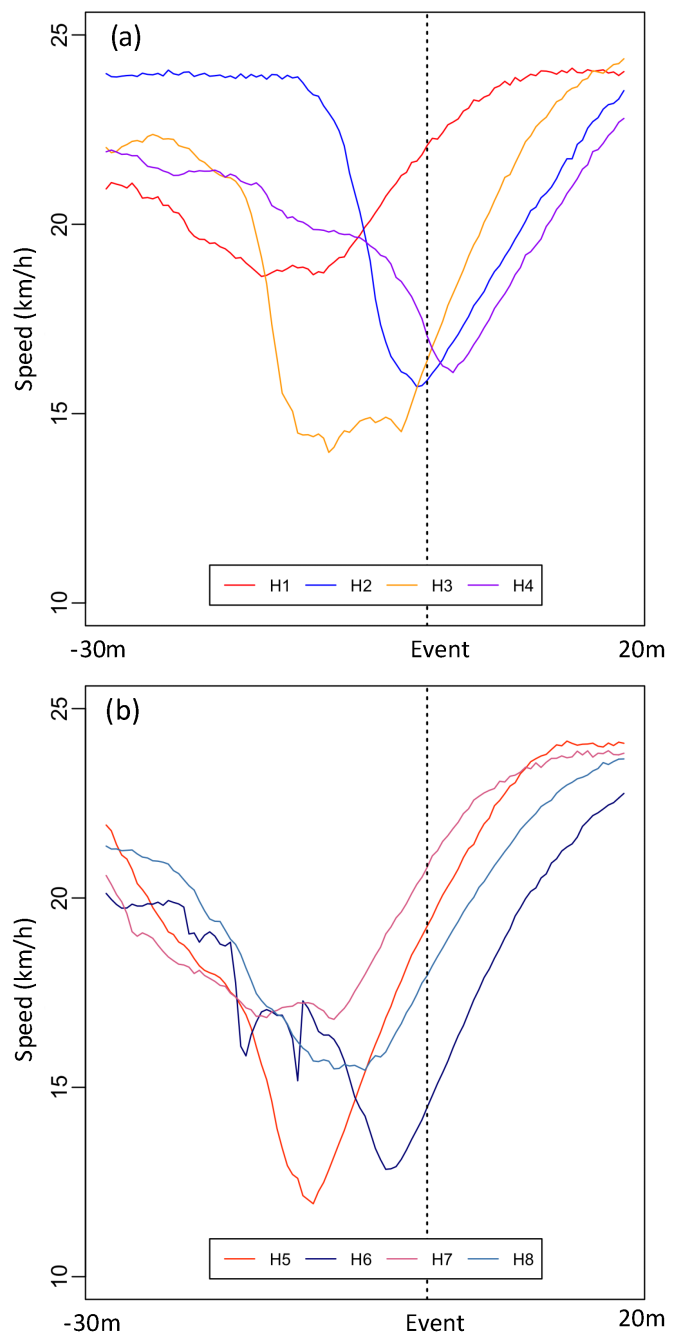

Figure 7: The comparison of crossing trajectories for road hazards: (a) Section 2; (b) Section 4

which is approximately $1 / 3$ of the bicycle length $(1.6 \mathrm{~m})$. The mean value of $0.5 \mathrm{~m}$-segment for 30 subjects is used to get speed-related trajectory figures, as shown in Figure 6 and Figure 7. Figure 6 shows subject riding speed performance on section 2 and section 4, with the eight road event occurrences marked and labeled. Figure 7 compares the specific 
crossing trajectories in the event window. Looking at all four events, cyclist speed minimums in the bike lane are lower, and further from the crash point. This shows that when using a bike lane, cyclists will slow down more for identified hazards, and sooner. As these curves are averages taken across subjects, multiple visible minimums in one curve may suggest hesitations in cyclist reactions. For example, H3 and H6 contain multiple minimums before the event, while $\mathrm{H} 2$ and $\mathrm{H} 5$ each have a single minimum before the event. This is evidence of subject uncertainty in reaction times for $\mathrm{H} 3$ and $\mathrm{H} 6$, while reaction timing is more certain for $\mathrm{H} 2$ and $\mathrm{H} 5$.

\section{Discussion}

This study developed a virtual reality bicycle simulation and designed a virtual city environment with the typical type of road hazard scenarios experience by cyclists. A controlled experiment with 30 subjects has explored how different road environments influence cyclist behavior regarding speed performance and bike lane keeping ability. A number of researchers have questioned the use of virtual simulation as a tool for discovering how road users actually behave on the roadway, as opposed to how well they can potentially perform (Evans 2004; Chan et al. 2010). This experiment noted that simulators do capture behavioral differences between cyclists in different bike lane configurations and traffic conditions, as well as speed reactions towards road hazards.

Regarding environmental factors, the road type (shared road and bike lane road) and traffic type (low traffic and high traffic) both exhibit significant interaction effects on both speed and bike lane departure measures. During shared road conditions, cyclists steered farthest from the right edge of the road when no traffic was present, but never strayed beyond the right half of the lane. Once traffic is introduced, cyclists held more closely to the right of the lane, but still not as close to the right as when a bike lane is present. This may suggest that cyclists are more comfortable remaining along the right side of the lane, but will not adhere closely to the right until this behavior is suggested by a bike lane. The existence of a bike lane did significantly improve cyclist lanekeeping performance, which was expected, and can support the previous study that well-maintained bicycle specific infrastructures improve bicycle safety (Vanparijs et al. 2015; Reynolds et al. 2009). To compare traffic conditions when a bike lane is present, low traffic leads to a significantly lower proportion of cyclist time out of the lane. This is because higher traffic can lead to scenarios that force bicyclists to swing out of the bike lane. For example, in hazard H6, a bus occupies and comes to a stop in the bike lane, which requires subjects to shift out of the lane in response. Regardless of traffic type factors, cyclists riding in high traffic show more caution. Specifically, they ride slower and have a greater tendency to stay in the lane. When cyclists encounter surrounding vehicles and road events, presumably, the perceived threat increases with higher surrounding traffic. Results show that higher traffic leads to a significantly larger standard deviation of speed when compared to low traffic. This means cyclists in high traffic are changing speed more frequently, most likely because there are more events to react to. These effects can be further analyzed by comparing the four specific road sections, which provide every combination of traffic and bike lane conditions. S3 had low traffic and a bike lane, and hosted the highest riding speed and lowest lane deviation, suggesting that this is the most comfortable condition for riders. The addition of a bike lane creates significantly greater differences in behavior between low and high traffic conditions, suggesting that the positive effect of a bike lane decreases significantly in high traffic. From a recent literature review (DOT 2015), most bike lane related studies focus on safety performance differences between a shared one-way road and separated bike lanes. The experiment findings in our bicycle simulation support previous surveys and studies. For example, Monesere et al. found that $71 \%$ of the cyclists surveyed felt that the separated bike lane made bicycling safer and easier; other studies have also found that separated bike lanes exhibit crash reductions when compared with similar streets without any bicycle infrastructure (Nosal and Miranda-Moreno 2012; Winters et al. 2013; Lusk et al. 2013; Harris et al. 2013; Teschke et al. 2012; Jensen, Rosenkilde, and Jensen 2007; Thomas and DeRobertis 2013). Studies analyzing crash data records arrive at similar results, but detailed key information that could influence conclusions are unclear, e.g. bicycle volumes (Chen et al. 2012), or an accurate description of facilities (Loo and Tsui 2010). However, bicycle simulation can provide a controlled road environment to precisely support or explain the findings from these observed reports.

As discussed, there were many accidents involving cyclists, and the majority of them happen due to conflict between cyclists and motor vehicle drivers. From the result, average Distance to Brake to Collision (DBC) and nondeceleration rates measured in this study show that cyclists do not provide uniform reactions to all hazards. Comparatively lower non-deceleration rates and a higher average DBC indicate that cyclists consider right turning cars as a greater danger than crossing pedestrians. The data provided also suggests that cyclists react more cautiously to hazard events when a bike lane is present. Event speed trajectories show that introduction of bike lanes causes overall safer reactions to hazards. Results indicate multiple minimums in average speed for $\mathrm{H} 3$ and $\mathrm{H} 6$, which suggests hesitant reaction timing among subjects during these hazards. $\mathrm{H} 3$ and $\mathrm{H} 6$ are the left crossing vehicle and the bus occupying the bike lane. These are both materialized hazards that could lead to a collision, and the reaction hesitations among subjects may suggests that cyclists are not sure what proper action to take during these scenarios. Public education for what cyclists should do during these specific scenarios could help reduce the occurrence of traffic incidents when the situations arise in real life. It is worth noting that the newly defined DBC is not a common value that can be assumed, but a variable that can change based on the nature of both the hazard and the cyclist. Compared with "distance to brake to stop formula", measuring DBC does not require cyclists to come to a complete stop. The fact is that not all cyclist reactions result in braking to a complete stop, and bike simulation could reflect that people show different reactions to different hazard types (e.g. vehicle or pedestrians). Continued work could further 
break down DBC to define the details regarding different subject reaction types (e.g. cautious, hesitant, aggressive reactions, etc.)

Some factors concerning how this study was carried out should be considered. The experiment course consisted of two sections without a bike lane, followed by two sections with a bike lane. This order was chosen so that bike lane behavior would not be considered by subjects until the lanes were introduced, but subjects may still have been affected by some elements of consecutive effects from the experiment design. Continued work with a greater subject count and randomized event order could help reduce the influence of consecutive effects from experiment design. As a pilot attempt for utilizing new technology in a bicycle simulation study, a major limitation of this study is the absence of an actual bicycle and use of a keyboard for input control. This will decrease the fidelity of participant experiences and might cause differences in bicyclist behavior from riding their actual bikes. Therefore, future studies could include monitoring behaviors within real world experiences, and comparison with in-lab experiments to distinguish the behaviour shift from VR simulation to field studies. Moreover, continued work could employ more additional indices for exploring cyclist behavior, such as physiological measures (Yang and Wu 2017; Mackenzie and Harris 2015; Vansteenkiste et al. 2013; 2014a; 2014b; Foulsham, Walker, and Kingstone 2011; Dicks, Button, and Davids 2010). For example, eye movement tracking could be useful to examine whether cyclists pay attention to similar patterns at any given road scenario or hazard events, and whether these patterns correlate with speed or lane position.

\section{Conclusion}

An increasing number of people are realizing the advantages of bicycling, and concerns and awareness for bicyclist safety have risen accordingly. Bicycle simulation has great potential to provide an in-depth resolution for examining detailed cyclist riding behaviour by exposing cyclists to potential life scenarios in a safe way, especially for road hazard perception and reaction. New technology has to be introduced for advancing these research methods. The present work took a first step attempt towards implementing a Head Mounted Display (Oculus Rift) into used VR technology for an immersive cyclist simulator.

By using the developed VR bike simulation, bicyclist responses to different road environments, as well as behavioral differences among different road hazard types are discussed to understand individual cyclist behavior. Results from road environments show that while the addition of a bike lane does provide a significant change in cyclist behavior in low traffic conditions, higher traffic results in less observable changes. This suggests that the existence of denser traffic can have a greater influence on cyclist behavior than bike lanes. This can provide valuable information to help shape existing guidelines for cyclist facilities based on traffic density. In addition, work done in this study provides a glimpse into the variability of responses cyclists give to different hazard types. These differences show that during the
Distance to Brake to Collison (DBC), when cyclists are reacting, they are also evaluating the danger of the hazard, as well as how to react. This realization opens a path to a new, more accurate method for reaction time estimation, which will consider road environment and hazard type, as well as cyclist hazard perception and reaction decision.

These findings reveal that a bike simulator designed with VR technology can be applied as an effective and safe way for providing useful insight into individual cyclist reactions to specific road scenarios or road hazards. It can also provide potential applications for engineers and for cyclist safety education or training. The VR cyclist simulation setup could also be useful to study cyclist hazard perception, the effects of bicyclist distraction (e.g. music, conversation, telephone, etc.), bicycle facility testing (e.g. low-quality lane markings, etc.), developing reasonable safety management strategies, training assessment or accident mitigation programs.

Our continued work currently focuses on developing a bicycle interface for integration into the bike simulation to improve control. The bicycle can provide self-balance and mimic the "fish-tailing" phenomena of a real bicycle. We believe the combination of a realistic virtual road environment, 360-degree immersive VR headset, and a high-fidelity bicycle interface can provide a full-immersion of simulation experience for further bicycle behavior studies.

\section{ACKNOWLEDGEMENTS}

This work has been financially supported by the $[\mathrm{Na}-$ tional Science Foundation] under Grant [0954579 and 1333524]; [China State Laboratories Open funding] under Grant [GZKF-201512]; [China Scholarship Council] under Scholarship [201035145]. We thank the contribution of Yuanchen Fang, Dustin Fong, John Margenson, Andre Mulia, Nicholas Price, Rafael Banis, and all the members from the Intelligent Human-Machine Systems Lab.

\section{REFERENCES}

[1] Alshaer, A.; Regenbrecht, H.; and OHare, D. 2017. Immersion factors affecting perception and behaviour in a virtual reality power wheelchair simulator. Applied ergonomics 58:1-12.

[2] Babu, S. V.; Grechkin, T. Y.; Chihak, B.; Ziemer, C.; Kearney, J. K.; Cremer, J. F.; and Plumert, J. M. 2011. An immersive virtual peer for studying social influences on child cyclists' road-crossing behavior. IEEE transactions on visualization and computer graphics 17(1):14-25.

[3] Beck, B.; Stevenson, M.; Newstead, S.; Cameron, P.; Judson, R.; Edwards, E. R.; Bucknill, A.; Johnson, M.; and Gabbe, B. 2016. Bicycling crash characteristics: an in-depth crash investigation study. Accident Analysis \& Prevention 96:219-227.

[4] Belgiovane, D. J., and Chen, C. C. 2016. Rcs measurements of bicycles and human riders for automotive radar. SAE Technical Paper.

[5] Cai, H., and Lin, Y. 2011. Modeling of operators' emotion and task performance in a virtual driving environment. International Journal of Human-Computer Studies 69(9):571-586. 
[6] Cai, H., and Lin, Y. 2012. An integrated head pose and eye gaze tracking approach to non-intrusive visual attention measurement for wide fov simulators. Virtual Reality 16(1):25-32.

[7] Cai, Q.; Lee, J.; Eluru, N.; and Abdel-Aty, M. 2016. Macro-level pedestrian and bicycle crash analysis: Incorporating spatial spillover effects in dual state count models. Accident Analysis \& Prevention 93:14-22.

[8] Cai, H.; Lin, Y.; and Cheng, B. 2010. Mimicking human driving behaviors autonomous vehicles in realistic traffic flow simulation. Journal of Automotive Safety and Energy 6(2):126-136.

[9] Chan, E.; Pradhan, A. K.; Pollatsek, A.; Knodler, M. A.; and Fisher, D. L. 2010. Are driving simulators effective tools for evaluating novice drivers hazard anticipation, speed management, and attention maintenance skills? Transportation research part F: traffic psychology and behaviour 13(5):343-353.

[10] Chen, P., and Shen, Q. 2016. A gps-based analysis of built environment influences on bicyclist route preferences. In Transportation Research Board 95th Annual Meeting, number 16-1948.

[11] Chen, L.; Chen, C.; Srinivasan, R.; McKnight, C. E.; Ewing, R.; and Roe, M. 2012. Evaluating the safety effects of bicycle lanes in new york city. American journal of public health 102(6):1120-1127.

[12] Colwell, J., and Culverwell, A. 2002. An examination of the relationship between cycle training, cycle accidents, attitudes and cycling behaviour among children. Ergonomics 45(9):640-648.

[13] Dan, G. 2012. Bicyclist behaviors \& crash risk.

[14] de Waard, D.; Edlinger, K.; and Brookhuis, K. 2011. Effects of listening to music, and of using a handheld and handsfree telephone on cycling behaviour. Transportation research part $F$ : traffic psychology and behaviour 14(6):626-637.

[15] Dicks, M.; Button, C.; and Davids, K. 2010. Examination of gaze behaviors under in situ and video simulation task constraints reveals differences in information pickup for perception and action. Attention, Perception, \& Psychophysics 72(3):706-720.

[16] DOT, U. 2015. Separated bike lane planning and design guide. NHTSA Report.

[17] Ducheyne, F.; De Bourdeaudhuij, I.; Lenoir, M.; and Cardon, G. 2014. Effects of a cycle training course on children's cycling skills and levels of cycling to school. Accident Analysis \& Prevention 67:49-60.

[18] El-Geneidy, A. M.; Krizek, K. J.; and Iacono, M. 2007. Predicting bicycle travel speeds along different facilities using gps data: A proof of concept model. In Proceedings of the 86th Annual Meeting of the Transportation Research Board, Compendium of Papers.

[19] Evans, L. 2004. Traffic safety science serving society. Bloomfield Hills, MI 179.
[20] Foulsham, T.; Walker, E.; and Kingstone, A. 2011. The where, what and when of gaze allocation in the lab and the natural environment. Vision research 51(17):19201931.

[21] Grechkin, T. Y.; Chihak, B. J.; Cremer, J. F.; Kearney, J. K.; and Plumert, J. M. 2013. Perceiving and acting on complex affordances: how children and adults bicycle across two lanes of opposing traffic. Journal of experimental psychology: human perception and performance 39(1):23.

[22] Harris, M. A.; Reynolds, C. C.; Winters, M.; Cripton, P. A.; Shen, H.; Chipman, M. L.; Cusimano, M. D.; Babul, S.; Brubacher, J. R.; Friedman, S. M.; et al. 2013. Comparing the effects of infrastructure on bicycling injury at intersections and non-intersections using a casecrossover design. Injury Prevention 19(5):303-310.

[23] Jensen, S. U.; Rosenkilde, C.; and Jensen, N. 2007. Road safety and perceived risk of cycle facilities in copenhagen. Presentation to AGM of European Cyclists Federation.

[24] Kay, J. J.; Savolainen, P. T.; Gates, T. J.; and Datta, T. K. 2014. Driver behavior during bicycle passing maneuvers in response to a share the road sign treatment. Accident Analysis \& Prevention 70:92-99.

[25] Khan, S., and Raksuntorn, W. 2001. Characteristics of passing and meeting maneuvers on exclusive bicycle paths. Transportation Research Record: Journal of the Transportation Research Board (1776):220-228.

[26] Kocamaz, M. K.; Gong, J.; and Pires, B. R. 2016. Vision-based counting of pedestrians and cyclists. In $A p$ plications of Computer Vision (WACV), 2016 IEEE Winter Conference on, 1-8. IEEE.

[27] Kosaka, H., and Noda, M. 2015. Education method for safe bicycle riding to evaluate actual cycling behaviors when entering an intersection. In International Conference on Human Interface and the Management of Information, 225-232. Springer.

[28] Legrand, F. D.; Joly, P. M.; Bertucci, W. M.; SoudainPineau, M. A.; and Marcel, J. 2011. Interactive-virtual reality (ivr) exercise: An examination of in-task and pre-topost exercise affective changes. Journal of Applied Sport Psychology 23(1):65-75.

[29] Lin, Y. 2010. i-drive, are we ready? Journal Of Automotive Safety And Energy 07(01):14-24.

[30] Lin, Y. 2017. Towards intelligent human-machine interactions human assistance systems (has). ASME Magazine Special Issue on Human-Machine Interactions.

[31] Loo, B. P., and Tsui, K. 2010. Bicycle crash casualties in a highly motorized city. Accident Analysis \& Prevention 42(6):1902-1907.

[32] Lusk, A. C.; Morency, P.; Miranda-Moreno, L. F.; Willett, W. C.; and Dennerlein, J. T. 2013. Bicycle guidelines and crash rates on cycle tracks in the united states. American journal of public health 103(7):1240-1248. 
[33] Mackenzie, A., and Harris, J. 2015. Using experts' eye movements to influence scanning behaviour in novice drivers. Journal of vision 15(12):367-367.

[34] Meijaard, J. P.; Papadopoulos, J. M.; Ruina, A.; and Schwab, A. L. 2007. Linearized dynamics equations for the balance and steer of a bicycle: a benchmark and review. In Proceedings of the Royal Society of London A: Mathematical, Physical and Engineering Sciences, volume 463, 1955-1982. The Royal Society.

[35] Morel, M.; Bideau, B.; Lardy, J.; and Kulpa, R. 2015. Advantages and limitations of virtual reality for balance assessment and rehabilitation. Neurophysiologie Clinique/Clinical Neurophysiology 45(4):315-326.

[36] NHTSA. 2010. Aashto guide for the development of bicycle facilities. NHTSA Report, US DOT.

[37] NHTSA. 2016. Traffic safety facts: Bicyclists and other cyclists. NHTSA Report, US DOT.

[38] Nosal, T., and Miranda-Moreno, L. F. 2012. Cycletracks, bicycle lanes, and on-street cycling in montreal, canada: A preliminary comparison of the cyclist injury risk. Technical report.

[39] Oculus, V. 2016. Oculus rift. Available from WWW:; https://www3.oculus.com/en-us/dk2.

[40] Plumert, J. M.; Kearney, J. K.; Cremer, J. F.; Recker, K. M.; and Strutt, J. 2011. Changes in childrens perception-action tuning over short time scales: Bicycling across traffic-filled intersections in a virtual environment. Journal of experimental child psychology 108(2):322-337.

[41] Plumert, J. M.; Kearney, J. K.; and Cremer, J. F. 2004. Children's perception of gap affordances: Bicycling across traffic-filled intersections in an immersive virtual environment. Child development 75(4):12431253.

[42] Proulx, F. R.; Schneider, R. J.; and Miranda-Moreno, L. F. 2016. Performance evaluation and correction functions for automated pedestrian and bicycle counting technologies. Journal of transportation engineering 142(3):04016002.

[43] Pulugurtha, S. S., and Thakur, V. 2015. Evaluating the effectiveness of on-street bicycle lane and assessing risk to bicyclists in charlotte, north carolina. Accident Analysis \& Prevention 76:34-41.

[44] Reynolds, C. C.; Harris, M. A.; Teschke, K.; Cripton, P. A.; and Winters, M. 2009. The impact of transportation infrastructure on bicycling injuries and crashes: a review of the literature. Environmental health 8(1):47.

[45] Schepers, P., and den Brinker, B. 2011. What do cyclists need to see to avoid single-bicycle crashes? Ergonomics 54(4):315-327.

[46] Schleinitz, K.; Petzoldt, T.; Krems, J. F.; and Gehlert, T. 2016. The influence of speed, cyclists age, pedaling frequency, and observer age on observers time to arrival judgments of approaching bicycles and e-bikes. Accident Analysis \& Prevention 92:113-121.
[47] Sherony, R., and Zhang, C. 2015. Pedestrian and bicyclist crash scenarios in the us. In Intelligent Transportation Systems (ITSC), 2015 IEEE 18th International Conference on, 1533-1538. IEEE.

[48] Stevens, E.; Plumert, J. M.; Cremer, J. F.; and Kearney, J. K. 2012. Preadolescent temperament and risky behavior: Bicycling across traffic-filled intersections in a virtual environment. Journal of pediatric psychology 38(3):285-295.

[49] Stevenson, M.; Johnson, M.; Oxley, J.; Meuleners, L.; Gabbe, B.; and Rose, G. 2014. Safer cycling in the urban road environment: study approach and protocols guiding an australian study. Injury prevention injuryprev-2014.

[50] Suzuki, M.; Miyanoue, K.; Takagawa, T.; and Tetsuo, Y. 2011. Bicycle collision analysis using vehicle driving simulator movic-t4. In 3rd International Conference on Road Safety and Simulation.

[51] SUZUKI, M.; MIYANOUE, K.; and Student, D. C. 2013. Development of bicycling simulator for analysis of traffic safety and flow.

[52] Teschke, K.; Harris, M. A.; Reynolds, C. C.; Winters, M.; Babul, S.; Chipman, M.; Cusimano, M. D.; Brubacher, J. R.; Hunte, G.; Friedman, S. M.; et al. 2012. Route infrastructure and the risk of injuries to bicyclists: a case-crossover study. American journal of public health 102(12):2336-2343.

[53] Thomas, B., and DeRobertis, M. 2013. The safety of urban cycle tracks: A review of the literature. Accident Analysis \& Prevention 52:219-227.

[54] Unity. 2016. Manual: Physics, wheel collider. Available from $W W W: ;$ Unity3D https://docs.unity3d.com/Manual/classWheelCollider.html.

[55] Vanparijs, J.; Panis, L. I.; Meeusen, R.; and de Geus, B. 2015. Exposure measurement in bicycle safety analysis: A review of the literature. Accident Analysis \& Prevention 84:9-19.

[56] Vansteenkiste, P.; Cardon, G.; DHondt, E.; Philippaerts, R.; and Lenoir, M. 2013. The visual control of bicycle steering: The effects of speed and path width. Accident Analysis \& Prevention 51:222-227.

[57] Vansteenkiste, P.; Van Hamme, D.; Veelaert, P.; Philippaerts, R.; Cardon, G.; and Lenoir, M. 2014a. Cycling around a curve: The effect of cycling speed on steering and gaze behavior. PloS one 9(7):e102792.

[58] Vansteenkiste, P.; Zeuwts, L.; Cardon, G.; Philippaerts, R.; and Lenoir, M. 2014b. The implications of low quality bicycle paths on gaze behavior of cyclists: A field test. Transportation research part F: traffic psychology and behaviour 23:81-87.

[59] Vansteenkiste, P. 2015. Visually guided steering of young and adult bicyclists during a slalom task. The role of visual information in the steering behaviour of young and adult bicyclists 109. 
[60] VirZoom, I. 2015. Virzoom. Available from WWW:; https://virzoom.com/.

[61] Wheeler, N.; Conrad, R.; and Figliozzi, M. A. 2010. A statistical analysis of bicycle rider performance: The impact of gender on riders performance at signalized intersections. In Proceedings 89th Annual Meeting Transportation Research Board January, volume 10, 14.

[62] Winters, M.; Harris, M.; Reynolds, C. C.; Cripton, P.; Chipman, M.; Cusimano, M.; Brubacher, J.; Friedman, S.; Monro, M.; Vernich, L.; et al. 2013. Bicyclists injuries and the cycling environment: The impact of route infrastructure. Washington, DC http://docs. trb. org/prp/13-2995. pdf.

[63] Wolfe, E. S.; Arabian, S. S.; Breeze, J. L.; and Salzler, M. J. 2016. Distracted biking: an observational study. Journal of trauma nursing: the official journal of the Society of Trauma Nurses 23(2):65.

[64] Xu, J., and Lin, Y. 2014. A networked multidrivers simulation platform for interactive driving behavior study. 20.1-20.8.

[65] Xu, C.; Yang, Y.; Jin, S.; Qu, Z.; and Hou, L. 2016. Potential risk and its influencing factors for separated bicycle paths. Accident Analysis \& Prevention 87:59-67.

[66] Yang, C.-Y., and Wu, C.-T. 2017. Primary or secondary tasks? dual-task interference between cyclist hazard perception and cadence control using cross-modal sensory aids with rider assistance bike computers. Applied ergonomics 59:65-72.

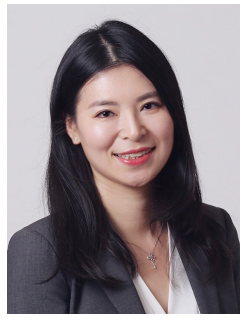

Jing $\mathrm{Xu}$ is a Ph.D. graduate in the Mechanical and Industrial Engineering Department at Northeastern University in Boston, Massachusetts. Her research interests include human factors, human behavior in virtual enviroment, networked multidriver simulation, connected vehicles technology, and physiological and behavioral analysis of human behaviors.

Yingzi Lin is the Director of

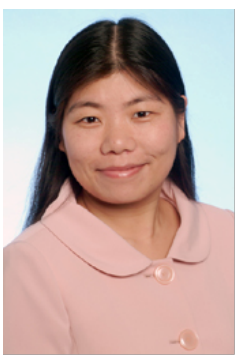
the Intelligent Human-Machine Systems Laboratory and an Associate Professor in the department of Mechanical and Industrial Engineering at Northeastern University. Her research interests include human machine interactions, human assistance systems, smart systems, and human factors in transportation and healthcare.

David Schmidt is a Ph.D. graduate in the Department of Bioengineering at Northeastern University. With experience in using wearable motion and physiological sensors, he is interested in wearables for human sensing, and how they can be used to collect relevant data for subject cognitive, task performance, and health measurements. 